\title{
The effect of conjugated linoleic acid on the fatty acid composition of different tissues and yolk lipids in pigeons
}

\author{
R. Aydin \\ Department of Animal Science, Kahramanmaras Sutcu Imam University, 40060 Kahramanmaras, Turkey
}

\begin{abstract}
Dietary conjugated linoleic acid (CLA) was reported to increase the levels of saturated fatty acids (SFA), to decrease monounsaturated fatty acids (MUFA) in egg yolk, liver and adipose tissue in chicken and quail. Hence, the objective of this study was to determine the effects of dietary CLA on the fatty acid composition of liver, breast muscle, abdominal adipose tissue and egg yolk lipids in pigeons. Eight established breeding pairs per group were fed either a commercially pelleted pigeon diet mixed with $0.5 \%$ safflower oil (SFO) or $0.5 \%$ CLA for 12 weeks. For fatty acid analyses, four eggs per group were collected at the $10^{\text {th }}$ week of feeding. At the end of the $12^{\text {th }}$ week of the CLA feeding, four pigeons per treatment were killed and liver, breast muscle and abdominal fat pads were obtained at necropsy. For fatty acid analyses, fats from liver, breast muscle, abdominal adipose tissue and egg yolks were extracted with chloroform : methanol $(2: 1, \mathrm{v} / \mathrm{v})$. Dietary CLA had no effect on the fatty acid composition of the liver compared to the control. However, dietary CLA caused a significant increase in the level of SFA and a decrease in the level of MUFA in breast muscle, adipose tissue and egg yolk. Breast muscle, adipose tissue and egg yolk from the CLA-fed pigeons had 1.8-, 1.6-, and 1.5-fold increases in the ratio of C16:0/C16:1(n-7), respectively. Also the ratio of C18:0/C18:1(n-9) in breast muscle, adipose tissue and egg yolk from the CLA group increased 1.4-, 2.2- and 1.9-fold, respectively, compared to the control. Relative CLA (\%) in the liver, breast muscle, adipose tissue and egg yolk from the CLA group was $0.71,1.30,2.14$ and 1.22\%, respectively. Control egg yolk contained only $0.06 \%$ CLA. This study showed that CLA altered the fatty acid composition of the related tissues and egg yolk when supplemented in the diet of pigeons.
\end{abstract}

Keywords: Conjugated linoleic acid, egg and tissue fatty acid compositions, pigeon

E-mail: rahimaydin@ksu.edu.tr

\section{Introduction}

Conjugated linoleic acid (CLA) is a mixture of positional and geometrical isomers of linoleic acid (C18:2 c-9, c-12) and has received much attention because of the many biological activities shown in animal models. CLA was first isolated from grilled ground beef (Ha et al., 1987) and found to be a potent anticarcinogen in several animal models (Ha et al., 1990; Ip et al., 1991; Ip et al., 1994). Some researchers reported that chicks fed CLA had significantly less growth suppression than control fed chicks when they were induced by endotoxin injection (Cook et al., 1993; Miller et al., 1994). Dietary CLA was shown to affect body composition in several animal species by acting on fatty acid metabolism. Recently, it was shown that CLA reduced body fat and increased lean body mass in rats (Park et al., 1997).

Dietary fats were shown to change the fatty acid composition of egg yolk, adipose tissue and liver of laying hens (Sim et al., 1972). CLA was incorporated into milk fat, tissue lipids and foetal and neonatal tissues when dams were fed CLA (Chin et al., 1994). It was also reported that CLA feeding caused significant changes in the fatty acid composition of the aorta, liver and plasma of rabbits (Lee, 1996). In the studies conducted on chickens, dietary CLA caused a significant increase in the level of SFA (mainly C16:0 and C18:0) and a decrease in the level of MUFA (mainly C16:1 n-7 and C18:1 n-9) in egg yolk (Chamruspollert \& Sell, 1999; Aydin et al., 2001). Another study conducted on quail showed that dietary CLA significantly altered the fatty acid composition of egg yolk and liver (Aydin \& Cook, 2004). It was shown that dietary CLA caused higher levels of saturated fatty acids (SFA) and lower levels of monounsaturated fatty acids (MUFA) by inhibiting stearoyl-CoA desaturase activity (Lee et al., 1998). Nutritional studies showed that CLA isomers were readily incorporated into animal tissues depending on its level in the diet (Ip et al., 1994; Banni et al., 1995; Kramer et al., 1998). It was also shown that CLA could 
be incorporated into the lipids of liver, muscle, adipose tissue and egg yolks from laying hens fed CLA (Aydin et al., 2001; Aydin \& Cook, 2005).

Hence, the objective of this study was to determine the effect of incorporating CLA in the diet on the fatty acid composition of the liver, muscle, abdominal adipose tissue, and egg yolk of pigeons.

\section{Materials and Methods}

CLA was synthesized from linoleic acid (99\% pure; NU Check Prep., Elysian, MN) by alkali isomerization and analysed for purity by a capillary gas chromatography (GC), as previously described (Ha et al., 1990; Chin et al., 1992). Purity of CLA was determined to exceed 95\% as total CLA isomers. Prepared CLA was stored under an argon atmosphere at $-20^{\circ} \mathrm{C}$ until used.

The pigeon house was divided into two sections and eight established breeding pairs per treatment were fed either a commercially pelleted pigeon diet (containing $150 \mathrm{~g}$ crude protein $/ \mathrm{kg}$ and $12.13 \mathrm{MJ}$ metabolisable energy $/ \mathrm{kg}$ ) mixed with $0.5 \%$ safflower oil (SFO, control) or $0.5 \%$ synthetically prepared CLA (contained $95 \%$ CLA) in the form of free fatty acid for 12 weeks. The experimental diets were mixed weekly and birds were fed fresh feed daily.

Four eggs from each group were collected for two consecutive days during the $10^{\text {th }}$ week of the feeding study. Eggs were broken and the yolks and albumen of the eggs were separated. The last traces of albumen were removed by rolling the egg yolk on filter paper. Egg yolks separated from albumens were kept in vials at $-20^{\circ} \mathrm{C}$ until analysis for fatty acid content. At the end of the $12^{\text {th }}$ week of the CLA feeding period, four pigeons per treatment were chosen at random and killed by means of carbon dioxide exposure. Livers, pectoralis (breast muscle) and abdominal fat pads from sacrificed pigeons were obtained at necropsy and their weights were recorded. Tissue samples were frozen at $-20^{\circ} \mathrm{C}$ until analysed for fatty acid composition. Fat from all tissues was extracted with chloroform : methanol $(2: 1 \mathrm{v} / \mathrm{v})$ according to the method of Folch et al. (1957). Fatty acid methyl esters (FAME) were prepared by reaction with $4 \% \mathrm{HCL}$ in methanol for $20 \mathrm{~min}$ at $60{ }^{\circ} \mathrm{C}$ and the composition of the FAME was determined by GC. Briefly, a Hewlett-Packard 5890 series II $\mathrm{GC}$ was fitted with a flame-ionization detector and 3396A integrator. A supercovax-10 fused silica capillary column $(60 \mathrm{~m} \mathrm{X} 0.32 \mathrm{~mm}$ i.d., $0.25 \mu \mathrm{m}$ film thickness) was used. Oven temperature was programmed from 50 to $200{ }^{\circ} \mathrm{C}$, increasing $20^{\circ} \mathrm{C}$ per min., held for $50 \mathrm{~min}$ and increasing $10^{\circ} \mathrm{C}$ per min to a final temperature of $230^{\circ} \mathrm{C}$, where it was held for $20 \mathrm{~min}$. Heptadecanoic acid (Sigma Chemical Co., St Louis, MO) was used as an internal standard. The FAME were identified by comparison of retention times with methylated fatty acid standards (Sigma Chemical Co., St Louis, MO and Nu-Chek Prep., Elysian, MN) and expressed as percentage of total FAME (Chin et al., 1992).

Differences in the fatty acid compositions of egg and tissues, with diet as main effect, were analysed statistically by using a t-test (SPSS software 10.0; Chicago, IL), with differences being considered significant at $\mathrm{P}<0.05$.

\section{Results}

Table 1 represents the effects of dietary CLA on the fatty acid profile of the liver in the pigeons. Feeding CLA to the pigeons did not cause a significant change in the fatty acid composition of the liver when compared to the control group ( $\mathrm{P}>0.05$ ). The relative level of CLA (as $\%$ of fatty acid methyl esters) in the liver was $0.71 \%$, although CLA was not detectable in the liver of pigeons fed the SFO diet.

The effect of feeding CLA on the fatty acid composition of the pigeon breast muscle is shown in Table 2 . The relative level of CLA (\%) in the breast muscle was 1.3\%. In contrast, CLA was not detectable in the breast muscle of pigeons fed the SFO diet. Pigeons fed CLA had increased levels of (as \% of fatty acid methyl esters) total SFA and decreased levels of total MUFA in the breast muscle when compared to the SFO group $(\mathrm{P}<0.05)$. A higher concentration of $\mathrm{C} 14: 0, \mathrm{C} 16: 0$ and a lower concentration of $\mathrm{C} 18: 1(\mathrm{n}-9)$ were found in the breast muscles of the CLA-fed pigeons when compared to the SFO group $(\mathrm{P}<0.001)$. However, the relative level (\%) of C18:0 in the breast muscles of the pigeons fed CLA was similar to the control group. In the present study, when CLA was added to the pigeon diet, the proportion of C18:1(n-9) decreased significantly from 27.6 to $21.3 \%$ of the total fatty acids in the breast muscle. In contrast, polyunsaturated fatty acids (PUFA) in the breast muscle of the pigeons fed the CLA diet did not differ significantly from those supplemented with the SFO diet. 
Table 1 Effect of feeding a commercial pelleted pigeon $\operatorname{diet}^{1}$ supplemented with $0.5 \%$ safflower oil (SFO) or conjugated linoleic acid (CLA) on the liver fatty acid compositions ${ }^{2}$ of pigeons

\begin{tabular}{|c|c|c|c|}
\hline \multirow{2}{*}{ Fatty acids } & \multicolumn{2}{|c|}{$\%$ of Total fatty acids (Means \pm s.e.) } & \multirow{2}{*}{ P-value } \\
\hline & SFO & $\mathrm{CLA}^{3}$ & \\
\hline $\mathrm{C} 14: 0$ & $0.18 \pm 0.02$ & $0.20 \pm 0.02$ & 0.48 \\
\hline $\mathrm{C} 16: 0$ & $19.7 \pm 2.31$ & $23.05 \pm 2.53$ & 0.367 \\
\hline C16:1(n-7) & $1.18 \pm 0.13$ & $0.95 \pm 0.13$ & 0.243 \\
\hline C18:0 & $27.81 \pm 3.92$ & $23.32 \pm 2.42$ & 0.367 \\
\hline C18:1(n-9) & $22.1 \pm 2.98$ & $19.46 \pm 3.35$ & 0.577 \\
\hline C18:2(n-6) & $23.13 \pm 3.08$ & $24.63 \pm 2.60$ & 0.723 \\
\hline$\alpha C 18: 3(n-3)$ & $0.12 \pm 0.02$ & $0.15 \pm 0.02$ & 0.425 \\
\hline $\mathrm{C} 20: 4(\mathrm{n}-6)$ & $5.78 \pm 1.17$ & $7.55 \pm 0.88$ & 0.271 \\
\hline$\Sigma \mathrm{CLA}$ & nd & $0.71 \pm 0.10$ & - \\
\hline$\Sigma$ SFA & $47.69 \pm 3.84$ & $46.56 \pm 0.38$ & 0.779 \\
\hline$\Sigma$ MUFA & $23.29 \pm 2.93$ & $20.41 \pm 3.38$ & 0.544 \\
\hline$\Sigma$ PUFA & $29.03 \pm 3.95$ & $33.03 \pm 3.41$ & 0.472 \\
\hline
\end{tabular}

${ }^{1}$ Commercial pigeon diet containing $150 \mathrm{~g}$ crude protein $/ \mathrm{kg}$ and $12.13 \mathrm{MJ}$ metabolisable energy $/ \mathrm{kg}$

Diet SFO - 99.5\% commercial pelleted diet plus $0.5 \%$ safflower oil

Diet CLA - 99.5\% commercial pelleted diet plus 0.5\% CLA (synthetically prepared and containing 95\% pure CLA)

${ }^{2}$ Values are means \pm s.e. (4 observations) expressed as percentage total fatty acid methyl esters

${ }^{3}$ CLA-95 was synthesized from linoleic acid (99\% pure); nd - not detectable

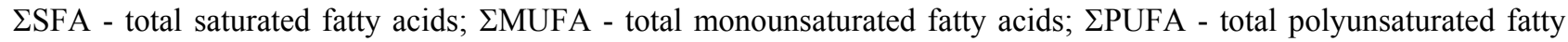
acids, including total CLA; ECLA - total conjugated linoleic acids

Table 2 Effect of feeding a commercially pelleted pigeon $\operatorname{diet}^{1}$ supplemented with $0.5 \%$ safflower oil (SFO) or conjugated linoleic acid (CLA) on the breast muscle fatty acid composition ${ }^{2}$ of pigeons

\begin{tabular}{|c|c|c|c|}
\hline \multirow{2}{*}{ Fatty acids } & \multicolumn{2}{|c|}{$\%$ of Total fatty acids (Means \pm s.e.) } & \multirow{2}{*}{ P-value } \\
\hline & SFO & $\mathrm{CLA}^{3}$ & \\
\hline $\mathrm{C} 14: 0$ & $0.35 \pm 0.01$ & $0.42 \pm 001$ & 0.005 \\
\hline $\mathrm{C} 16: 0$ & $19.0 \pm 0.57$ & $21.5 \pm 0.28$ & 0.009 \\
\hline C16:1(n-7) & $3.8 \pm 0.11$ & $2.4 \pm 0.11$ & 0.012 \\
\hline $\mathrm{C} 18: 0$ & $15.9 \pm 0.50$ & $17.2 \pm 0.64$ & 0.139 \\
\hline C18:1(n-9) & $27.6 \pm 0.86^{\mathrm{a}}$ & $21.3 \pm 1.16$ & 0.005 \\
\hline C18:2(n-6) & $26.7 \pm 1.31$ & $28.0 \pm 0.27$ & 0.363 \\
\hline$\alpha C 18: 3(n-3)$ & $0.35 \pm 0.03$ & $0.38 \pm 0.02$ & 0.659 \\
\hline $\mathrm{C} 20: 4(\mathrm{n}-6)$ & $6.3 \pm 0.79$ & $7.5 \pm 0.58$ & 0.254 \\
\hline$\Sigma$ CLA & nd & $1.30 \pm 0.15$ & - \\
\hline$\Sigma$ SFA & $35.25 \pm 1.06$ & $39.12 \pm 0.74$ & 0.024 \\
\hline$\Sigma$ MUFA & $31.40 \pm 1.09$ & $23.70 \pm 1.21$ & 0.003 \\
\hline$\Sigma$ PUFA & $33.35 \pm 1.87$ & $37.18 \pm 0.61$ & 0.10 \\
\hline
\end{tabular}

${ }^{1}$ Commercial pigeon diet containing $150 \mathrm{~g}$ crude protein/kg and $12.13 \mathrm{MJ}$ metabolisable energy $/ \mathrm{kg}$

Diet SFO - 99.5\% commercial pelleted diet plus $0.5 \%$ safflower oil

Diet CLA - 99.5\% commercial pelleted diet plus 0.5\% CLA (synthetically prepared and containing 95\% pure CLA)

${ }^{2}$ Values are means \pm s.e. (4 observations) expressed as percentage total fatty acid methyl esters

${ }^{3}$ CLA-95 was synthesized from linoleic acid (99\% pure); nd - not detectable

$\Sigma$ SFA - total saturated fatty acids; $\Sigma$ MUFA - total monounsaturated fatty acids; $\Sigma$ PUFA - total polyunsaturated fatty acids, including total CLA; $\Sigma$ CLA - total conjugated linoleic acids 
Table 3 Effect of feeding a commercially pelleted pigeon $\operatorname{diet}^{1}$ supplemented with $0.5 \%$ safflower oil (SFO) or conjugated linoleic acid (CLA) on the adipose tissue fatty acid composition ${ }^{2}$ of pigeons

\begin{tabular}{lrrr}
\hline \multirow{2}{*}{ Fatty acids } & \multicolumn{2}{c}{ \% of Total fatty acids (Means \pm s.e.) } & P-value \\
\cline { 2 - 3 } & \multicolumn{1}{c}{ SFO } & \multicolumn{1}{c}{ CLA $^{3}$} & \\
C14:0 & $0.7 \pm 003$ & $1.6 \pm 0.06$ & 0.001 \\
C16:0 & $19.8 \pm 0.25$ & $24.1 \pm 0.84$ & 0.003 \\
C16:1(n-7) & $5.8 \pm 0.48$ & $4.5 \pm 0.46$ & 0.084 \\
C18:0 & $8.9 \pm 0.61$ & $14.7 \pm 1.48$ & 0.008 \\
C18:1(n-9) & $43.0 \pm 0.94$ & $31.7 \pm 0.55$ & $<0.001$ \\
C18:2(n-6) & $21.2 \pm 1.12$ & $20.7 \pm 0.65$ & 0.693 \\
$\alpha$ C18:3(n-3) & $0.56 \pm 0.05$ & $0.49 \pm 0.06$ & 0.217 \\
C20:4(n-6) & $0.04 \pm 0.00$ & $0.07 \pm 0.01$ & - \\
CCLA & nd & $2.14 \pm 0.37$ & $<0.001$ \\
SSFA & $29.40 \pm 0.66$ & $40.40 \pm 1.14$ & $<0.001$ \\
SMUFA & $48.80 \pm 1.28$ & $36.20 \pm 0.67$ & 0.312 \\
S PUFA & $21.80 \pm 1.17$ & $23.40 \pm 0.75$ &
\end{tabular}

${ }^{1}$ Commercial pigeon diet containing $150 \mathrm{~g}$ crude protein $/ \mathrm{kg}$ and $12.13 \mathrm{MJ}$ metabolisable energy $/ \mathrm{kg}$

Diet SFO - 99.5\% commercial pelleted diet plus $0.5 \%$ safflower oil

Diet CLA - 99.5\% commercial pelleted diet plus 0.5\% CLA (synthetically prepared and containing 95\% pure CLA)

${ }^{2}$ Values are means \pm s.e. (4 observations) expressed as percentage total fatty acid methyl esters

${ }^{3}$ CLA-95 was synthesized from linoleic acid (99\% pure); nd - not detectable

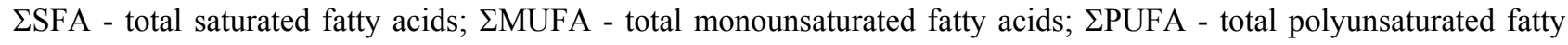
acids, including total CLA; $\Sigma$ CLA - total conjugated linoleic acids

Table 4 Effect of feeding a commercially pelleted pigeon $\operatorname{diet}^{1}$ supplemented with $0.5 \%$ safflower oil (SFO) or conjugated linoleic acid (CLA) on pigeons' egg yolk fatty acid composition ${ }^{2}$

\begin{tabular}{lrrr}
\hline \multirow{2}{*}{ Fatty acids } & \multicolumn{2}{c}{ \% of Total fatty acids (Means \pm s.e.) } & P-value \\
\cline { 2 - 3 } & \multicolumn{1}{c}{ SFO } & \multicolumn{1}{c}{ CLA $^{3}$} & 0.005 \\
C14:0 & $0.24 \pm 0.02$ & $0.34 \pm 0.02$ & $<0.001$ \\
C16:0 & $21.0 \pm 0.27$ & $27.2 \pm 0.36$ & 0.191 \\
C16:1(n-7) & $1.9 \pm 0.12$ & $1.6 \pm 0.17$ & $<0.001$ \\
C18:0 & $12.0 \pm 0.19$ & $16.9 \pm 0.28$ & $<0.001$ \\
C18:1(n-9) & $44.1 \pm 0.52$ & $32.5 \pm 0.23$ & 0.543 \\
C18:2(n-6) & $18.8 \pm 0.65$ & $18.3 \pm 0.42$ & 0.236 \\
$\alpha$ C18:3(n-3) & $0.28 \pm 0.02$ & $0.34 \pm 0.33$ & 0.246 \\
C20:4(n-6) & $1.62 \pm 0.04$ & $1.60 \pm 0.07$ & $<0.001$ \\
LCLA & $0.06 \pm 0.01$ & $1.22 \pm 0.06$ & $<0.001$ \\
SSFA & $33.24 \pm 0.36$ & $44.44 \pm 0.33$ & $<0.001$ \\
LMUFA & $46.00 \pm 0.58$ & $34.10 \pm 0.30$ & 0.443 \\
I PUFA & $20.76 \pm 0.67$ & $21.46 \pm 0.45$ &
\end{tabular}

${ }^{1}$ Commercial pigeon diet contained $150 \mathrm{~g}$ crude protein $/ \mathrm{kg}$ and $12.13 \mathrm{MJ}$ metabolisable energy $/ \mathrm{kg}$

Diet SFO - 99.5\% commercial pelleted diet plus $0.5 \%$ safflower oil

Diet CLA - 99.5\% commercial pelleted diet plus $0.5 \%$ CLA (synthetically prepared and contained $95 \%$ pure CLA)

${ }^{2}$ Values are means \pm s.e. (4 observations) expressed as percentage total fatty acid methyl esters

${ }^{3}$ CLA-95 was synthesized from linoleic acid (99\% pure)

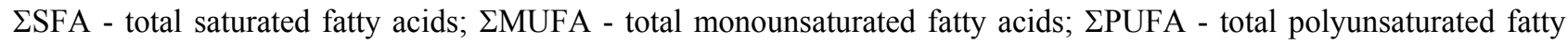
acids, including total CLA; ECLA - total conjugated linoleic acids 
Dietary CLA also caused significant changes in the fatty acid profile of adipose tissue of pigeons fed CLA compared to the SFO group (Table 3). The content of total CLA (\%) in the abdominal adipose tissue was $2.14 \%$. Similar to the fatty acid composition of the liver and breast muscle, CLA was not detectable in the abdominal adipose tissue of pigeons fed the SFO diet. Dietary CLA increased the levels of C14:0, C16:0 and $\mathrm{C} 18: 0$ and decreased the level of $\mathrm{C} 18: 1(\mathrm{n}-9)$ significantly in the abdominal adipose tissue compared to the control $(\mathrm{P}<0.05)$. The ratio of MUFA/SFA was approximately 1.9 -fold higher in the abdominal adipose tissue from the pigeons fed $0.5 \%$ SFO compared to those given the $0.5 \%$ CLA diet.

Table 4 shows the effects of dietary CLA on the fatty acid composition of pigeons' egg yolk. Feeding CLA in a low-fat diet significantly increased the SFA and decreased the MUFA in the egg yolk. In contrast, PUFA in the egg yolks of the CLA fed pigeons did not significantly differ from those supplemented with the SFO diet. The C14:0 content of the egg yolks from the CLA group was significantly higher than the control $(\mathrm{P}<0.01)$. The ratios of C16:0/C16:1(n-7) and C18:0/C18:1(n-9) in the egg yolk from the CLA group increased about 1.5- and 1.9-fold, respectively, when compared to those fed the SFO diet. In the present study, hens fed CLA had yolks with a 23 -fold increase in total CLA (as a percentage of fatty acid methyl esters) when compared to the yolks of hens fed the SFO diet ( $1.22 \%$ and $0.06 \%$, respectively). In the present study, dietary CLA was shown to have no effect on the levels of C18:2(n-6) and C20:4(n-6) in the egg yolk.

\section{Discussion}

CLA is a group of naturally occurring fatty acids and was shown to inhibit the activity of liver stearoyl-CoA desaturase (Lee et al., 1998; Park et al., 2000), an enzyme that catalyzes the insertion of a double bond between the $\mathrm{C} 9$ and $\mathrm{C} 10$ atoms of $\mathrm{C} 16: 0$ or $\mathrm{C} 18: 0$ in the formation of $\mathrm{C} 16: 1(\mathrm{n}-7)$ and $\mathrm{C} 18: 1(\mathrm{n}$ 9), respectively. Therefore, CLA was shown to cause significant changes in the fatty acid composition by altering the level of MUFA and SFA in egg yolk (Chamruspollert \& Sell, 1999; Du et al., 1999; Jones et al., 2000; Aydin et al., 2001), milk (Kelly et al., 1998) and breast muscle from Cobb 500 broilers (Sirri et al., 2003).

In the present study, feeding CLA to pigeons did not cause a significant change in the fatty acid composition of the liver, the main site of de novo fatty acid synthesis, when compared to the control group. Similar to the findings of the present study, it was shown that a diet containing $0.5 \%$ CLA did not influence the levels of C16:1(n-7) and C18:1(n-9) significantly in liver from quail (Aydin \& Cook, 2004). However, adding even $0.25 \%$ CLA to the diet of quail significantly altered the level of C16:0 in the liver. In the same study, diets containing $2 \%$ or more CLA caused alterations in the level of C18:1(n-9) of the liver (Aydin \& Cook, 2004). It was also shown that when quail were fed a diet containing CLA, only the level of C16:0 in the liver increased significantly and not C18:0 (Aydin \& Cook, 2004). It was reported that the use of 5\% CLA in a diet significantly changed the fatty acid composition of the liver in broiler chickens (Badinga et al., 2003). In another study conducted on single comb white leghorn laying hens, a diet containing 0.5\% CLA significantly increased the levels of SFA (mainly C14:0, C16:0, and C18:0) and decreased the levels of MUFA (mainly C16:1, n-7 and C18:1, n-9) in the liver (Aydin \& Cook, 2005). However, in the present study it was observed that dietary CLA had no effects on the liver fatty acid composition in the pigeon (Table 1).

In the present study, in contrast to the effects of CLA on the fatty acid composition of pigeon liver, dietary CLA increased the levels of C14:0 and C16:0 significantly in the breast muscle compared to the control group $(\mathrm{P}<0.01)$ (Table 2). However, the relative level $(\%)$ of $\mathrm{C} 18: 0$ in the breast muscle of pigeons fed CLA was similar to the control group. In a recent study conducted on chickens, it was shown that $2 \%$ CLA affected the levels of MUFA (mainly C16:1, n-7 and C18:1, n-9), but not the levels of SFA in breast fillet (Sirri et al., 2003). In the present study, when CLA was incorporated into the pigeon diet, the level of C18:1(n-9) decreased from 27.6 to $21.3 \%$ of the total fatty acids in the breast muscle (Table 2). Pigeons fed CLA had increased levels of total SFA and decreased levels of total MUFA in the breast muscles as compared to the SFO group (Table 2). In contrast, the PUFA in the breast muscles of the pigeons fed the CLA diet did not differ significantly from those supplemented with the SFO diet.

In the present study, similar to the fatty acid profile of the liver and breast muscle, CLA was not detectable in the abdominal adipose tissue of pigeons fed the SFO diet (Table 3). Pigeons fed CLA had increased levels (\%) of total SFA and decreased levels of total MUFA in the adipose tissue. The ratio of MUFA/SFA was approximately 2-fold higher in the abdominal adipose tissue from the pigeons fed the SFO diet compared to those given the CLA diet. Dietary CLA increased the levels of C14:0, C16:0 and C18:0 and 
decreased $(\mathrm{P}<0.01)$ the level of $\mathrm{C} 18: 1(\mathrm{n}-9)$ in the abdominal adipose tissue compared to the control. Similarly, in a study conducted in pigs, it was shown that CLA differentially modified the fatty acid composition in subcellular fractions of muscle and adipose tissue (Demaree et al., 2002). In another study conducted in pigs, dietary CLA was shown to increase the levels of C14:0, C16:0, and C18:0 and decreased the level of C18:1(n-9) significantly in the adipose tissue (Corino et al., 2003). However, in a study conducted on chickens, dietary CLA had no effect on the levels of C14:0 and C16:0 in the adipose tissue (Aydin \& Cook, 2005). In the same study, CLA decreased the levels of C16:1(n-7) and C18:1(n-9) and increased the level of C18:0 significantly in the adipose tissue (Aydin \& Cook, 2005).

As previously reported in chickens (Lee, 1996), dietary CLA caused similar changes in the fatty acid composition of pigeons' egg yolk. In the present study, feeding CLA in a low-fat diet significantly increased the level of SFA and decreased the level of MUFA in the egg yolk $(\mathrm{P}<0.05)$. In contrast, the PUFA in the egg yolk of the CLA fed pigeons did not differ significantly from those supplemented with the SFO diet. The level of C14:0 of the egg yolk from the CLA group was significantly higher than the control $(\mathrm{P}<0.01)$. The ratios of $\mathrm{C} 16: 0 / \mathrm{C} 16: 1(\mathrm{n}-7)$ and $\mathrm{C} 18: 0 / \mathrm{C} 18: 1(\mathrm{n}-9)$ in the egg yolk from the CLA group increased about 1.5and 1.9-fold, respectively, compared to those fed the control diet. In another study conducted on chickens, the ratios of $\mathrm{C} 16: 0 / \mathrm{C} 16: 1(\mathrm{n}-7)$ and $\mathrm{C} 18: 0 / \mathrm{C} 18: 1(\mathrm{n}-9)$ in the egg yolk from the CLA fed group were reported to increase about 1- and 1.5-fold, respectively, when compared to those fed the control diet (Aydin et al., 2001). It was also shown that adding olive oil (rich in C18:1, n-9) completely prevented the CLA-induced increase in the levels of C14:0, C16:0 and C18:0 and the CLA-induced decrease in C18:1(n-9) in egg yolk from chickens fed CLA (Aydin et al., 2001). Although dietary CLA had no effect on the concentration of yolk C18:2(n-6), the level (\%) of C20:4(n-6) in the yolk was decreased significantly in eggs from CLA-fed hens (Aydin et al., 2001). In the present study dietary CLA did not significantly influence the levels of C18:2(n-6) and C20:4(n-6) of the pigeon egg yolks. Pigeons fed CLA had yolks with a 23-fold increase in total CLA (as a percentage of fatty acid methyl esters) when compared to yolks of hens fed the control diet $(0.06 \%$ and $1.22 \%$, respectively). Previously, it was shown that egg yolks from the CLA-fed chickens could be enriched 17-fold in total CLA (as a percentage of fatty acid methyl esters) when compared to egg yolks of hens fed the control $(0.11 \%$ and $1.91 \%$, respectively) (Aydin et al., 2001). Since yolk fat has a crucial role as an energy source and essential nutrients in the avian embryo development, significant alteration in the fatty acid composition of egg yolk will have adverse effects on embryo survival, as shown by Aydin et al. (2001) and Aydin \& Cook (2004).

\section{Conclusion}

CLA is a group of naturally occurring fatty acids which affects the fatty acid composition of the tissues and egg yolk by inhibiting the stearoyl-CoA desaturase enzyme (Park et al., 2000). Dietary CLA influences the tissue and egg yolk fatty acid composition in a time and dose-dependent manner (Aydin \& Cook, 2004). In the light of the previous experiments conducted in various species, it was suggested that dietary CLA influenced the fatty acid composition of different tissues and egg yolk differently in the pigeons.

\section{References}

Aydin, R. \& Cook, M.E., 2004. The effect of dietary conjugated linoleic acid on egg yolk fatty acids and hatchability in Japanese quail. Poult. Sci. 83, 2016-2022.

Aydin, R. \& Cook, M.E., 2005. The influence of conjugated linoleic acid enriched tallow on egg hatchability and quality in chicken. Int. Poult. Sci. 4(8), 536-542.

Aydin, R., Pariza, M.W. \& Cook, M.E., 2001. Olive oil prevents the adverse effects of dietary conjugated linoleic acid on chick hatchability and egg quality. J. Nutr. 131, 800-806.

Badinga, L., Selberg, K.T., Dinges, A.C., Comer, C.W. \& Miles, R.D., 2003. Dietary conjugated linoleic acid alters hepatic lipid content and fatty acid composition in broiler chickens. Poult. Sci. 82, 111-116.

Banni, S., Day, B.W., Evans, R.W., Corongiu, F.P. \& Lombardi, B., 1995. Detection of conjugated diene isomers of linoleic acid in liver lipids of rats fed a choline-devoid diet indicates that the diet does not cause lipoperoxidation. J. Nutr. Biochem. 6, 281-289.

Chamruspollert, M. \& Sell, J.L., 1999. Transfer of dietary conjugated linoleic acid to egg yolks of chickens. Poult. Sci. 78, 1138-1150. 
Chin S.F., Storkson, J.M., Albright, K.J., Cook, M.E. \& Pariza, M.W., 1994. Conjugated linoleic acid is a growth factor for rats as shown by enhanced weight gain and improved feed efficiency. J. Nutr. 124, 2344-2349.

Chin, S.F., Storkson, J.M., Ha, Y.L. \& Pariza, M.W., 1992. Dietary sources of conjugated dienoic isomers of linoleic acid, a newly recognized class of anti carcinogens. Food Comp. Anal. 5, 185-197.

Cook, M.E., Miller, C.C., Park, Y. \& Pariza, M.W., 1993. Immune modulation by altered nutrient metabolism: nutritional control of immune-induced growth depression. Poult. Sci. 72, 1301-1305.

Corino, C., Magni, S., Pastorelli, G., Rossi, R. \& Mourot, J., 2003. Effect of conjugated linoleic acid on meat quality, lipid metabolism, and sensory characteristics of dry-cured hams from heavy pigs. J. Anim. Sci. 81, 2219-2229.

Demaree, S.R., Gilbert, C.D., Mersmann, H.J. \& Smith, S.B., 2002. Conjugated linoleic acid differentially modifies fatty acid composition in subcellular fractions of muscle and adipose tissue but not adiposity of postweanling pigs. J. Nutr. 132, 3272-3279.

Du, M., Ahn, D.U. \& Sell, J.L., 1999. Effect of dietary conjugated linoleic acid on the composition of egg yolk lipids. Poult. Sci. 78, 1639-1645.

Folch, J., Lees, M. \& Sloane-Stanley, G.H., 1957. A simple method for the isolation and purification of total lipides from animal tissues. J. Biol. Chem. 226, 497-509.

Ha, Y.L., Grimm, N.K. \& Pariza, M.W., 1987. Anticarcinogens from fried ground beef: Heat-altered derivatives of linoleic acid. Carcinogenesis 8, 1881-1887.

Ha, Y.L., Storkson, J.M. \& Pariza, M.W., 1990. Inhibition of benzo(a)pyrene-induced mouse fore stomach neoplasia by conjugated dienoic derivatives of linoleic acid. Cancer Res. 50, 1097-1101.

Ip, C., Chin, S.F., Scimeca, J.A. \& Pariza, M.W, 1991. Mammary cancer prevention by conjugated dienoic derivative of linoleic acid. Cancer Res. 51, 6118-6124.

Ip, C., Singh, M., Thompson, H.J. \& Scimeca, J.A., 1994. Conjugated linoleic acid suppresses mammary carcinogenesis and proliferative activity of the mammary gland in the rat. Cancer Res. 54, 1212-1215.

Jones, S., Ma, D.W.L., Robinson, F.E., Field, C.J. \& Clandinin, M.T., 2000. Isomers of conjugated linoleic acid (CLA) are incorporated into egg yolk lipids by CLA-fed laying hens. J. Nutr. 130, 2002-2005.

Kelly, M.L., Berry, J.R., Dwyer, D.A., Griinari, J.M., Chouinard, P.Y., Van Amburgh, M.E. \& Bauman, D.E., 1998. Dietary fatty acid sources affect conjugated linoleic acid concentrations in milk from lactating dairy cows. J. Nutr. 128, 881-885.

Kramer, J.K.G., Sehat, N., Dugan, M.E.R., Mossoba, M.M., Yurawecz, M.P., Roach, J.A.G., Eulitz, K., Aalhus, J.L., Schaefer, A.L. \& Ku, Y., 1998. Distributions of conjugated linoleic acid (CLA) isomers in tissue lipid classes of pigs fed a commercial CLA mixture determined by gas chromatography and silver ion-high performance liquid chromatography. Lipids 33, 549-558.

Lee, K.N., 1996. Conjugated linoleic acid and lipid metabolism. Doctoral thesis, University of WisconsinMadison, WI, USA. pp. 96-120.

Lee, K.N., Pariza, M.W. \& Ntambi, J.M., 1998. Conjugated linoleic acid decreases hepatic stearoyl-CoA desaturase mRNA expression. Biochem. Biophys. Res. Comm. 248, 817-821.

Miller, C.C., Park, Y., Pariza, M.W. \& Cook, M.E., 1994. Feeding conjugated linoleic acid to animals partially overcomes catabolic response due to endotoxin injection. Biochem. Biop. Res. Comm. 198, 1107-1112.

Park, Y., Albright, K.J., Liu, W., Cook, M.E. \& Pariza, M.W., 1997. Effect of conjugated linoleic acid on body composition in mice. Lipids 32, 853-858.

Park, Y., Storkson, J.M., Ntambi, J.M., Cook, M.E., Sih, C.J. \& Pariza, M.W., 2000. Inhibition of hepatic stearoyl-CoA desaturase activity by trans-10, cis-12 conjugated linoleic acid and its derivatives. Biochim. Biop. Acta 1486, 285-292.

Sim, J.S., Bragg, D.B. \& Hodgson, G.C., 1972. Effect of dietary animal tallow and vegetable oil on fatty acid composition of egg yolk, adipose tissue and liver of laying hens. Poult. Sci. 52, 51-57.

Sirri, F., Tallarico, N., Meluzzi, A. \& Franchini, A., 2003. Fatty acid composition and productive traits of broiler fed diets containing conjugated linoleic acid. Poult. Sci. 82, 1356-1361. 